\title{
Plasma levels of cortisol and oxytocin, and uterine activity after cervical artificial insemination in the ewe
}

\author{
Eric Houdeau ${ }^{\mathrm{a} *}$, Pierre RAYNAL ${ }^{\mathrm{a}}$, Pierre-Guy MARneT $^{\mathrm{b}}$, \\ Guy GERMAIN $^{\mathrm{c}}$, Pierre MORMÈDE ${ }^{\mathrm{d}}$, Bernadette RosSANO ${ }^{\mathrm{a}}$, \\ Régine MONNERIE ${ }^{\mathrm{a}}$, Marie-Jeanne PRUD'HOMME ${ }^{\mathrm{a}}$ \\ ${ }^{a}$ Laboratoire de Neurobiologie des Fonctions Végétatives, INRA, Jouy-en-Josas, France \\ b Équipe Associée INRA/ENSAR de Recherches sur la Traite, Rennes, France \\ ${ }^{\mathrm{c}}$ Unité de Physiologie Animale, INRA, Jouy-en-Josas, France \\ ${ }^{\mathrm{d}}$ Unité de Neurogénétique et Stress, INSERM/INRA, Institut François Magendie, \\ Bordeaux, France
}

(Received 30 April 2002; accepted 25 July 2002)

\begin{abstract}
The objective was to compare in the ewe the effects of easy and difficult procedures for artificial insemination (AI) (as related to rapid or poor accessibility of the cervix, respectively) on plasma cortisol (CORT) and oxytocin (OT), and uterine motility. All AI were simulated using a catheter empty of semen to study genital and environmental stimuli only. In experiment 1, 40 ewes were sampled after AI, and whether it was an easy or difficult procedure was reported for each animal. While CORT concentrations rose to a similar amount in all ewes, whatever the AI procedure, a significant OT response occurred after a difficult procedure only $(n=18)(17.4 \pm 1.7$ versus $12.7 \pm 0.7 \mathrm{pg} \cdot \mathrm{mL}^{-1}$ before AI, $p<0.05$ ). In experiment 2 , uterine activity was monitored in 4 ewes using an implantable telemetric transmitter equipped with an intrauterine pressure catheter. An increased uterine activity occurred during $2 \pm 1$ min after an easy $\mathrm{AI}(n=5)$, whereas the evoked activity lasted for $15 \pm 4 \mathrm{~min}$ after a difficult $\mathrm{AI}(p<0.001, n=7)$. A similar long-lasting response occurred after OT administration (100 mIU, i.v.). We concluded that the increase in uterine motility after a difficult AI resulted from a reflex release of OT, and not to a "stress" effect.
\end{abstract}

artificial insemination / cortisol / oxytocin / uterine contractions / telemetry

* Correspondence and reprints

E-mail: houdeau@jouy.inra.fr 


\section{INTRODUCTION}

In mammals, it is well established that uterine contractions facilitate the transit of spermatozoa through the female genital tract $[8,18,22]$. However, excessive uterine motility or an abnormal propagation of contractions along the uterus may compromise correct sperm transport towards the oviducts, and reduce fertility in ewes $[27,47]$ as in women $[22,25]$.

In the ewe, the structure of the cervical canal complicates transcervical or intrauterine artificial insemination (AI), and semen is usually deposited in the posterior cervical os (i.e. cervical AI) [4, 16]. However, reduced fertility is commonly observed using this procedure when compared with mating or the laparoscopic intrauterine deposition of semen [4]. It has been reported that an increase in uterine activity occurs in response to mechanical stimulation of the vagina during the periovulatory period [34], or following estrogen pretreatment [21], since it is well known that ovarian steroid levels modulate genital sensory nerve reflex pathways [37]. In the estrus ewe, this supports the idea that a change in the motor pattern may occur when the speculum is inserted and opened into the vagina, and may account for low fertility when this procedure is used for cervical AI. According to earlier studies, vaginal dilation at estrus is effective in evoking a reflex release of oxytocin (OT) from the pituitary gland $[1,35$, 38], which in turn stimulates uterine motility [12]. In the ewe, although Prud' homme and Rousseau [34] reported that a hypophysectomy abolished the uterine response to vaginal stimulation with a speculum, suggesting a reflex release of OT, no study has investigated OT secretion during routine procedures for cervical AI in this species.

On the contrary, an impairment of sperm transport has also been reported in manipulated ewes [31, 46], which was attributed to a stress effect during handling for AI [17]. Using electromyography, Van der Weyden
[49] reported that environmental disturbances during estrus (such as the presence of an observer in the stable) induced an increase in uterine activity. Since plasma cortisol (CORT) levels remain unchanged after mating in the ewe, and that uterine motility was not stimulated, or very briefly (less than $1 \mathrm{~min}$ ) [12], it is suggested that the absence of normal mating stimuli, together with stress during the AI procedure, may affect uterine motility for a long period.

During cervical AI in ewes, easy conditions for insemination require rapid localization of the cervical entrance, site of semen deposition, the limitation of vaginal stimulation with the speculum, and minimum additional stress [4]. However, factors such as difficulties in restraining the animal after insertion of the speculum, or poor accessibility of the cervical entrance lead to difficult conditions for AI, and may enhance stress as well as the intensity of vaginal stimulation. The aim of the present experiments was to compare the effects of easy and difficult procedures for cervical $\mathrm{AI}$ in ewes on (i) CORT and OT levels when AI was carried out during routine zootechnical procedures, and (ii) intrauterine pressure changes, used as an index for uterine motility. In order to study genital and environmental stimuli only, AI was simulated using a catheter empty of semen.

\section{MATERIALS AND METHODS}

\subsection{Animals and treatments}

Forty-four Prealpine ewes were obtained from the Institut National de la Recherche Agronomique (INRA, France) breeding colony. All animals were adults (aged 2 to $5 \mathrm{yr}), 14$ were primiparous and 30 multiparous (1 to 3 lambs) and weighed about $55 \mathrm{~kg}$ (range: 49 to $72 \mathrm{~kg}$ ). They were housed under natural light conditions, and all animals were fed a standard diet for nonpregnant ewes, with water ad libitum. Estrus 
synchronization was obtained by intra-vaginal sponges containing $40 \mathrm{mg}$ of a progestagen analog (Fluorogestone Acetate; Chrono. Gest, Intervet, France) for 14 days, followed by equine chorionic gonadotrophin (eCG) injection (400 IU, im). Under these conditions, estrus was obtained 36 to $48 \mathrm{~h}$ after sponge removal and the optimum time for a single insemination was $55 \pm 1 \mathrm{~h}$ after eCG injection [4]. The handling of ewes for $\mathrm{AI}$ and surgical procedures for telemetry were performed in compliance with the recommendations of the Food and Agriculture Organization of the United Nations and French laws concerning the protection of animals.

\subsection{Experiment 1}

\subsubsection{Artificial insemination and blood sampling}

In a group of 40 ewes, animals were handled for cervical AI as for a standard procedure. Estrus synchronization was performed in groups of 10 ewes at $24 \mathrm{~h}$ intervals, so as to enable the insemination of all animals $55 \pm 1 \mathrm{~h}$ after the injection of eCG [4]. The day before the experiment, the animals were housed in individual boxes near the site where AI would take place. All AI were performed with a standard cervical AI procedure in ewes [4]. All AI were carried out using an empty catheter, with the same operator, and two technicians securely held the animal by putting the hind legs over a rail. Blood samples were collected using sterile, evacuated Vacutainer heparinized tubes (Becton Dickinson, Meylan, France). The ewe was removed from the box, and a control blood sample was taken 1 min before handling for AI. The speculum (IMV, L'Aigle, France) was introduced 8 to $10 \mathrm{~cm}$ into the vagina, and was carefully opened ( 2 to $3 \mathrm{~cm}$ according to the individual) to localize the entry of the cervix. When AI was completed, the ewe was carefully placed on the ground and returned to its box. A series of blood samples were then taken at 5, 10, 15, 20, $30 \mathrm{~min}$, 1 and $2 \mathrm{~h}$ after AI. The samples were placed on ice and then centrifuged for $15 \mathrm{~min}$ at $2000 \times g$ at $2-4{ }^{\circ} \mathrm{C}$ within $30 \mathrm{~min}$ of sampling. Plasma samples were stored at $-80{ }^{\circ} \mathrm{C}$ until the hormone assays. The total duration of $\mathrm{AI}$, from insertion to withdrawal of the speculum, was measured as the mean (s) \pm SEM. During AI, the intensity of genital stimulation was scored in relation to: (1) "easy AI", when the operator reported easy localization of the cervix entrance before insemination, (2) "difficult AI", when the operator described difficulties in localizing the cervical entrance with the speculum before inserting the catheter.

\subsubsection{Hormone assays}

Plasma CORT concentrations were measured on duplicate samples using a radioimmunoassay (RIA), as described by ConteDevolx et al. [6], after ethanol extraction. The antibody, a gift from Charles Oliver (Marseille, France), was raised in rabbits, and exhibited $6 \%$ cross-reactivity with corticosterone. Tritiated cortisol $\left(\left[1,2,6,7-{ }^{3} \mathrm{H}\right]-\right.$ cortisol, Amersham, England) was used as the tracer and dextran-coated charcoal as the adsorbant for the unbound fraction. The detection limit was of $0.1 \mathrm{ng} \cdot \mathrm{mL}^{-1}$. The intra- and inter-assay coefficients of variation were 7.3 and $12.3 \%$, respectively. The results were expressed as mean plasma concentrations (ng. $\left.\mathrm{mL}^{-1} \pm \mathrm{SEM}\right)$.

Plasma OT concentrations were determined using EIA, as previously described by Marnet et al. [30]. Because of the short half-life of OT (half-distribution: 2 to $4 \mathrm{~min}$, and half-elimination: 20 to $25 \mathrm{~min}$ according to species $[15,19,41]$ including ewes (P.-G. Marnet, unpublished data), plasma levels were measured in the samples collected during the 20 min period after AI. Briefly, OT was extracted from $500 \mu \mathrm{L}$ of plasma using a C18 sep-pak extraction cartridge (millipore), eluted on methanol and vacuum-dried under centrifugation (speed vac, Sauvant). 
EIA is a competitive immunoassay performed on the reconstituted sample in $100 \mu \mathrm{L}$ of EIA buffer. Its specificity is the use of a monoclonal anti-fragment $\mathrm{Fc}$ of rabbit immunoglobin for attachment of the specific anti-OT on the wall of the microtiter plate, and competition with a tracer labeled with acetylcholine esterase. The EIA showed $0.3 \%$ cross-reactivity with arginine vasopressin, $0.15 \%$ with lysine vasopressin, and no cross-reaction $\left(<10^{-5} \%\right)$ with prostaglandin $F 2 \alpha$. The detection limit was lower than $1.5 \mathrm{pg} \cdot \mathrm{mL}^{-1}$. The intra- and interassay coefficients of variation were 4.6 and $12.6 \%$, respectively. The results were expressed as mean plasma concentrations (pg. $\left.\mathrm{mL}^{-1} \pm \mathrm{SEM}\right)$.

\subsection{Experiment 2}

\subsubsection{Surgical implantation of the telemetric transmitter}

In 4 multiparous ewes, intra-uterine pressure (IUP) changes were monitored using an implantable telemetric transmitter equipped with a fluid-filled sensor catheter (type TL11M3-D70-CCP; Data Sciences International, St. Paul, Minnesota, USA). Surgery was carried out under general halothane anaesthesia $\left(2.5 \%\right.$ in $1.5 \mathrm{~mL} \cdot \mathrm{min}^{-1}$ of oxygen) after the prior i.v. injection of a mixture of pentobarbital $\left(3 \mathrm{mg} \cdot \mathrm{kg}^{-1}\right)$ and thiopental $\left(10 \mathrm{mg} \cdot \mathrm{kg}^{-1}\right)$. The uterus was exposed by mid-ventral laparotomy, and a trans-uterine puncture was made to insert the tip of the pressure-sensitive catheter (1.2 $\mathrm{mm}$ diameter) into the lumen of the uterine body. The catheter was then secured to the uterine wall with sutures. The body of the telemetric transmitter was fixed to the abdominal wall and the abdomen was closed in two layers. Standard post-operative care of the animals consisted of a daily treatment with Penicillin Sarbach $\left(1 \cdot 10^{6} \mathrm{IU}, \mathrm{im}\right)$ (Solvay Pharma, Suresnes, France), for 5 days.

\subsubsection{Telemetric recording of uterine activity}

After a 10-day recovery period, estrus synchronization was performed as described above. One week before the injection of $\mathrm{eCG}$, the ewes were brought to the recording room and placed unrestrained in individual boxes with free access to food and water. During this period, the animals were visited daily to allow them to become accustomed to the experimental environment. A telemetric receiver (type RMC-1, Data Sciences Int.) was placed above the animal, and connected by a radioanalogic signal adapter (type R11-CPA, Data Sciences Int.) and an amplifier to an ES 1000 Gould recorder (Gould France, Longjumeau). Telemetric signals were also recorded on a PC equipped with BioBench hardware and software (National Instruments, Austin, Texas, USA) and sampled one per second. Intra-uterine pressure changes were recorded daily $(6 \mathrm{~h}$ per day) from 4 days before to 3 days after the eCG injection. The estrus period was verified when the average amplitude and frequency of uterine contractions were maximum, as described by Lehrer et al. [23, 24]. At the time of AI, IUP changes were monitored continuously, and the following procedures were applied. In 2 ewes $(n=5$ experiments), the speculum was inserted into the vagina, and opened by pressure on the grips; the catheter empty of semen was then inserted on contact with the entry of the cervix (easy AI). In 2 other animals ( $n=7$ experiments), the same procedure was applied, but the operator searched for the cervical entrance by manipulating the speculum, so as to mime difficulties in localizing it (difficult AI). All ewes were submitted to only one AI procedure per sexual cycle, at $55 \pm 1 \mathrm{~h}$ after eCG administration as in Experiment 1, on 3 successive sexual cycles. To check the effects of the two treatments in a same animal, IUP changes were recorded in one ewe following each of the easy and difficult AI procedures. 
All procedures were carried out with the same operator from Experiment 1, so that the effects of easy and difficult AI on IUP changes would be independent of the operator. For quantitative analysis, uterine activity was rated by calculating the integral of the curve (AUC \pm SEM) using BioBench software over a 2 min period immediately before AI (control period), and every $2 \mathrm{~min}$ after withdrawal of the speculum for $1 \mathrm{~h}$. The results were expressed as the percentage of control uterine activity. In order to test the reactivity to OT (Syntocinon, Sandoz), 3 ewes were treated with OT (100 mIU, i.v.) at the end of the experimental period, and uterine activity was recorded for $1 \mathrm{~h}$.

\subsection{Statistics}

All statistical analyses were performed using SigmaStat 2.0 software. The main effects of two variables (AI procedure and time after $\mathrm{AI}$ ) and their interaction were estimated on plasma OT and CORT levels (Experiment 1), and on IUP changes (Experiment 2), by two-way ANOVA. When significant effects were found $(p<0.05)$, the Bonferroni test was used for comparisons with control values, and to check the difference between the means of plasma concentrations and the means of AUC values after AI. In Experiment 1, the difference in total duration of the AI treatment between "easy" and "difficult" procedures was compared using an unpaired $t$-test, and a $p<0.05$ was considered as significant.

\section{RESULTS}

\subsection{Experiment 1}

Among the 40 ewes used in this study, 17 animals were scored as undergoing an "easy AI" and 18 a "difficult AI", respectively. Five ewes had to be eliminated from the experiment because they displayed abundant secretions and required vaginal clean- ing before insemination. Nine primiparous ewes were present in the "difficult AI" group $(50 \%)$, while 3 occurred in the "easy AI" group (18\%). The total duration (mean \pm SEM) of the insemination procedure was significantly increased during difficult AI $(43 \pm 4 s)$ when compared with easy AI $(25 \pm 3 \mathrm{~s})(p<0.001)$.

\subsubsection{Cortisol}

After the removal of ewes from their boxes, individual plasma CORT levels before the experiment ranged from 5.0 to $39.1 \mathrm{ng} \cdot \mathrm{mL}^{-1}$. No difference was found in control mean concentrations between "easy AI" $\left(14.5 \pm 2.2 \mathrm{ng} \cdot \mathrm{mL}^{-1}\right)$ and "difficult AI" $\left(15.6 \pm 1.5 \mathrm{ng} \cdot \mathrm{mL}^{-1}\right)$ ewes. The ANOVA revealed a significant effect of the AI procedure $(p<0.01)$ and time after $\mathrm{AI}(p<0.001)$ on CORT concentrations, but no interaction between the factors $(p>0.05)$. Plasma CORT levels were significantly higher $(p<0.001)$ than control values in all samples during the $30 \mathrm{~min}$ period after AI in both groups of animals (Fig. 1). During the same period, no significant difference in mean concentrations was observed between the "easy AI" and "difficult AI" groups (Fig. 1).

\subsubsection{Oxytocin}

Individual plasma OT levels before the experiment ranged from 3.6 to $27.1 \mathrm{pg} \cdot \mathrm{mL}^{-1}$. The mean control concentrations reached $11.5 \pm 1.7 \mathrm{pg} \cdot \mathrm{mL}^{-1}$ and $12.7 \pm 0.7 \mathrm{pg} \cdot \mathrm{mL}^{-1}$ in the "easy AI" and "difficult AI" groups of ewes, respectively (not significant). The ANOVA revealed a significant effect of the AI procedure on OT concentrations $(p<0.01)$. The mean OT concentration was significantly increased 5 min after a "difficult AI" procedure $\left(17.4 \pm 1.7 \mathrm{pg} \cdot \mathrm{mL}^{-1} ; p<0.05\right)$, and then returned to the baseline (Fig. 2). In ewes belonging to the "easy AI" group, no significant difference in plasma OT levels was observed compared to the control value, whatever the time after AI (Fig. 2). 

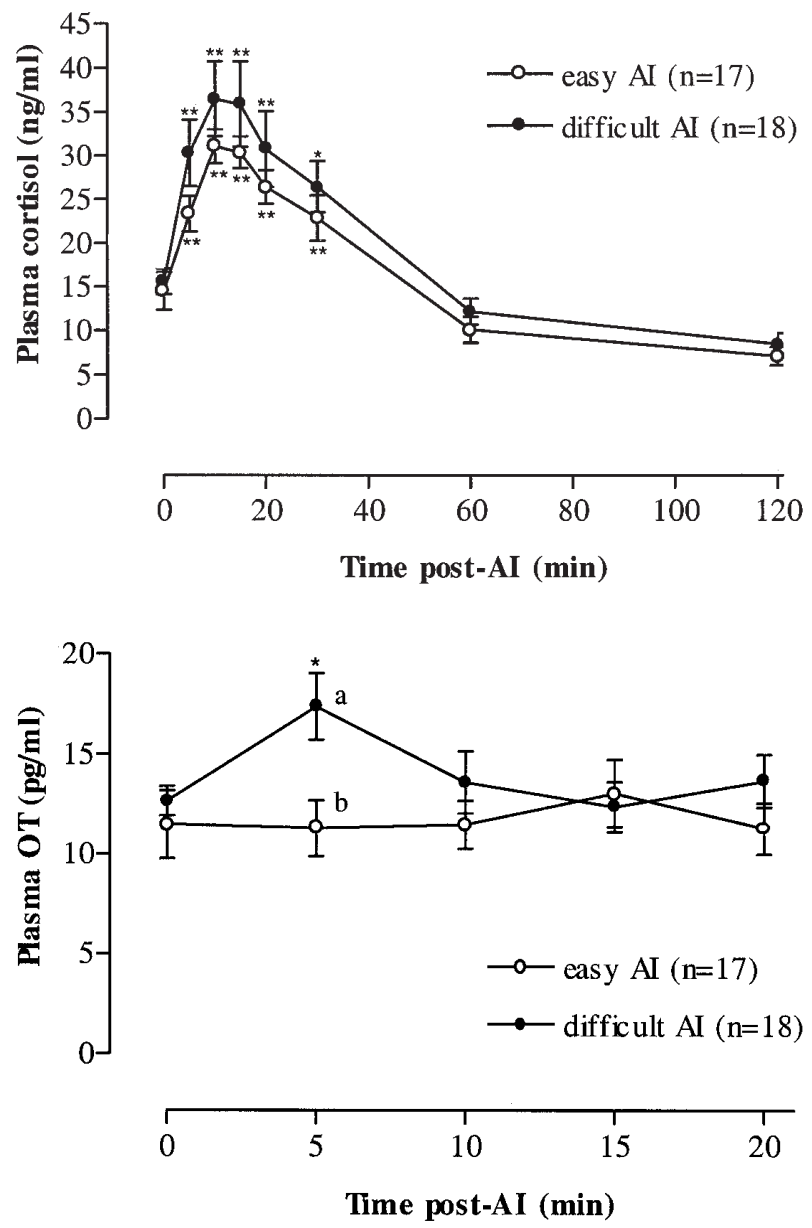

Figure 1. Mean plasma levels of CORT before and after easy or difficult procedures for simulated cervical AI. Data are means \pm SEM. $* p<0.05, * * p<0.001$ compared with control values. $n$ : number of animals.

Figure 2. Mean plasma levels of OT after easy or difficult procedures for simulated cervical AI. Data are means \pm SEM. A significant increase in OT concentrations was observed $5 \mathrm{~min}$ after difficult AI. $* p<0.05$ compared with control values, and ${ }^{\mathrm{a}, \mathrm{b}}$ differ $p<0.01$ between treatments. $n$ : number of animals.

\subsection{Experiment 2}

\subsubsection{Uterine activity after simulation of $A I$ and the effect of OT administration}

A representative control recording of IUP changes before AI is shown in Figure 3a. In all the ewes studied, the uterus displayed rhythmic contractile activity ( 1 to 3 contractions per min), with each contraction lasting 7-20 s. The mean amplitude of uterine contractions varied between ewes (range: 15-35 $\mathrm{cm} \mathrm{H}_{2} \mathrm{O}$ ) and within the same animal, during successive estrus cycles (data not shown). Movements of operators in and out of the recording room did not affect this pattern of uterine activity.

At the time of simulated AI, an increase in uterine motor activity was observed in all animals (easy and difficult AI) (Figs. 3b and $3 \mathrm{c}$ ). A uterine contraction occurred at each successive step during insemination, i.e. handling for the restraint of ewes before $\mathrm{AI}$, introduction and opening of the speculum into the vagina, and finally insertion of the catheter on contact with the cervical entrance. At the end of AI, two patterns of motor activity occurred, depending on the insemination procedure. The comparison of 
(a)

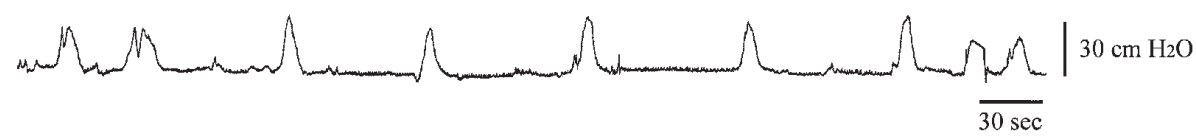

(b)

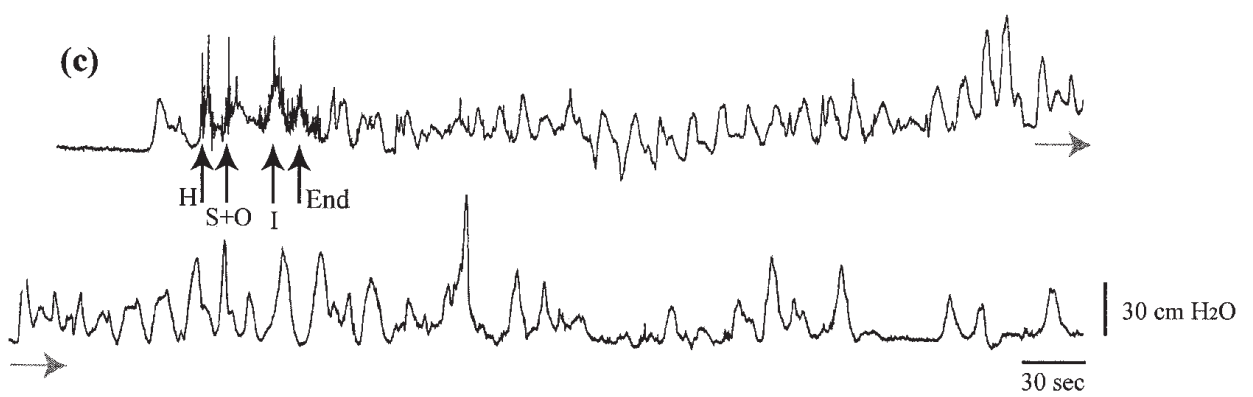

(d)

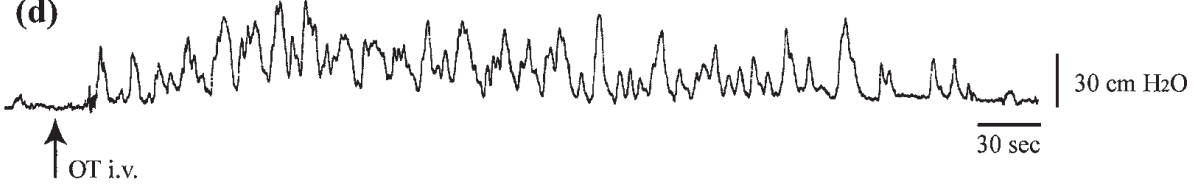

Figure 3. Direct telemetric intrauterine pressure recordings in the estrus ewe before (a), during and after simulation of easy (b) and difficult (c) procedures for cervical AI. Note the sustained rise in uterine motility after the end of stimulation in (c) when a difficult AI was performed (the two tracings are consecutive, as indicated by the gray arrow). (d) Intrauterine pressure changes in response to OT (100 mIU, i.v.). The technical insemination procedure in (b) and (c) can be broken down as follows: $\mathrm{H}$ : handling of animals to prepare for artificial insemination; $\mathrm{S}+\mathrm{O}$ : insertion and opening of the speculum; I: simulation of insemination with a catheter empty of semen; End: withdrawal of the speculum.

easy and difficult AI procedures in a same ewe revealed that the difference in evoked uterine activity resulted from a difference in stimulation treatment only (not shown). When easy AI was performed $(n=5)$ (Fig. 3b), the frequency of uterine contractions increased for $2 \pm 1 \mathrm{~min}$, and reached its maximum within the first minute after withdrawal of the speculum $(3.4 \pm 2.2$ contractions per min versus $1.2 \pm 0.5$ before the experiment). Uterine activity consisted of irregular contractions, sometimes of an amplitude greater than $60 \mathrm{~cm} \mathrm{H}_{2} \mathrm{O}$ (Fig. 3b). Following the integration of IUP records, a significant effect of the AI procedure and time after AI was found on uterine activity $(p<0.001)$, as well as a significant interaction between the two factors $(p<0.001)$. In the "easy" group of ewes, the uterine activity was significantly greater during the 

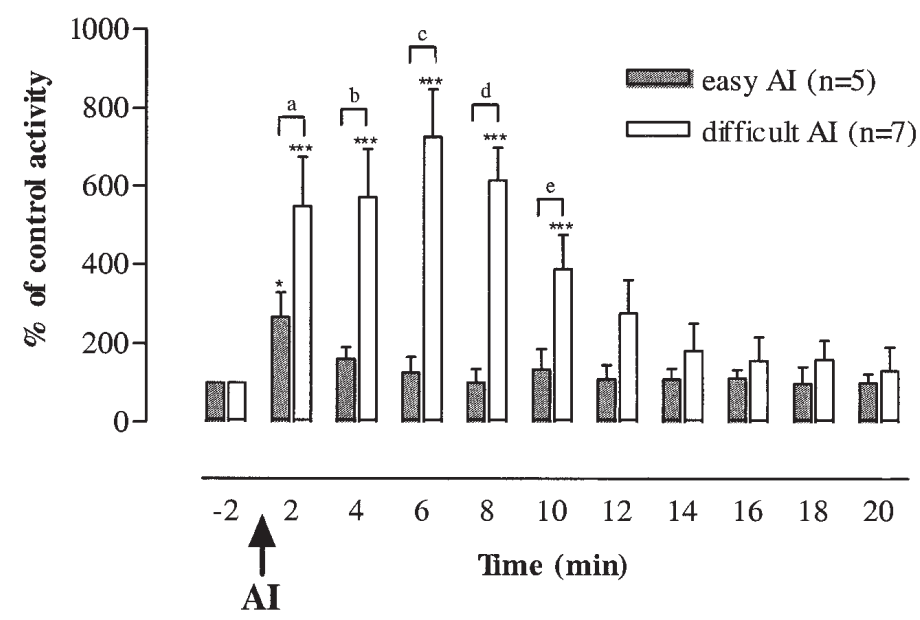

Figure 4. Integrated intrauterine pressure changes during successive 2 min periods following simulation of easy or difficult AI procedures. The values are expressed as a percentage of control activity (mean \pm SEM) calculated for the 2 min period just before the experiment $(-2)$. An easy AI resulted in a transient increase in uterine activity, whereas the rise in activity was significant for 10 min when a difficult AI was carried out. $n$ : number of experiments. $* p<0.05, * * * p<0.001$ compared with the control period, and a,b,c,d,e $p<0.001$ difference between easy and difficult AI procedures for each level of time.

2 min period immediately following AI, when compared with the control period $(p<0.05)$ (Fig. 4). By contrast, when a difficult AI was carried out $(n=7)$, the increase in uterine activity lasted far after the end of stimulation, i.e. $15 \pm 4$ min after withdrawal of the speculum (Fig. 3c). The integration of IUP records showed that a significant increase in uterine activity was maintained for 10 min after the end of stimulation, when compared with the control period $(p<0.001)$ (Fig. 4). In 5 of 7 experiments, IUP did not return to the baseline between uterine contractions during the maximum phase of uterine activity (Fig. 3c). Similar patterns of IUP changes were observed following the intravenous injection of OT (100 mIU), resulting in a sharp increase in uterine activity that lasted for $10 \pm 3 \min (n=3)$ (Fig. 3d).

\section{DISCUSSION}

The present study provides evidence that a rise in plasma levels of CORT and OT occurs after routine procedures for cervical AI in the ewe. Because AI was performed using a catheter empty of semen, it is concluded that these endocrine responses were due to environmental and genital stimuli associated with the handling of animals and the AI procedure only. By comparison, earlier studies in the same species had reported that stimuli associated with mating, such as olfactory, visual and tactile signals, and then coitus did not modify plasma levels of CORT and OT [12, 26].

In the ewe, adverse environmental stimuli increase uterine activity [3, 49], and this 'stress' effect may affect fertility [17, 31, 46]. In experiment 1 , plasma CORT was measured, since it is accepted that changes in circulating CORT concentrations constitute a sensitive index of the response to environmental stimuli [7]. For operators following standard breeding procedures, the accessibility of the site of semen deposition is a limiting factor to the rapid achievement of AI. It is therefore suggested that 
difficulties in localizing the cervical entrance increase the amount of stimuli during AI. An easy cervical AI procedure is commonly observed in multiparous ewes because the high degree of distensibility of the vaginal canal after multiple births often permits rapid localization of the cervix without further stimulation. By contrast, a difficult AI procedure is often encountered in primiparous ewes, and is commonly observed in nulliparous ewes. Our study reveals that CORT levels were significantly raised following both easy and difficult AI. However, since the AI procedure was carried out in all animals, it cannot be ruled out that increases in CORT concentrations were due to handling the ewes only, and were thus unrelated to AI stimulation itself. The important point is that no significant difference in CORT concentrations was noted between the two groups of animals. This indicates that conditions of discomfort for ewes during a difficult AI procedure did not result in more stressful conditions when compared with an easy AI.

Plasma levels of OT prior to AI were low in both groups of animals, and were within the same range as those reported in the same species during the periovulatory period [43, 50]. An increase in circulating OT was observed after difficult AI, while no change to OT concentrations occurred following easy insemination. It is well established that mechanical stimulation of the vagina (e.g. vaginal distension) evokes a reflex release of OT, the so-called "Ferguson" reflex [9], in ewes as in other species [1, 9, 20, 35, 38]. During difficult AI, the fact that more vaginal stimulation occurred with the speculum, and that the duration of the insemination procedure was significantly longer than with easy AI ( $\times 2$, this study) probably accounted for the rise in circulating OT. Therefore, our findings support the idea that the degree of the vaginal canal distensibility is a limiting factor in evoking a reflex release of OT during routine zootechnical AI procedures. This is consistent with the observations made by Schams et al. [42] in cows, who reported that AI did not induce an OT response in adults, whereas a rise in OT levels was commonly observed in nulliparous animals.

Experiment 2 aimed to investigate whether the intensity of genital stimulation during an AI procedure can stimulate uterine activity. In our study, the telemetric monitoring of IUP changes provided an accurate and reliable tool enabling direct records of motor activity of the uterus in conscious animals. During estrus, uterine activity consisted of regular contractions of high amplitude, a motor pattern fully consistent with the observations of Lehrer et al. [23, 24] using the same technique. In our experiments, the fact that genital stimulation throughout the AI procedure always elicited an increase in uterine activity was consistent with previous studies conducted in the same species [24], as in mares [48] and in women [39]. In addition, we showed that the uterine activity did not return to the baseline when AI was accomplished, and that the uterus remained stimulated up to $20 \mathrm{~min}$ following a difficult AI. According to Prud'homme and Rousseau [34], the activation of genital tract motility during $\mathrm{AI}$ is due to a spinal reflex involving the sympathetic nervous system and noradrenaline release from the uterine nerve terminals. However, a uterine response of long duration after a difficult AI cannot be explained in terms of noradrenaline release, since the reflex activation of the sympathetic nerve fibers stopped after withdrawal of the speculum [34]. On the contrary, the uterus displays high responsiveness to OT during estrus $[2,13,26]$. As demonstrated in the present study, the intravenous injection of OT increased uterine activity in a pattern similar to that described in response to the genital stimulation of difficult AI. It therefore appears that the increase in uterine motility after a difficult AI followed an elevation in circulating OT levels as measured in experiment 1 , indicating a temporal relationship between the reflex release of OT and the period of increased uterine motility. The same correlation has been reported 
in mares by Madill et al. [29], who demonstrated that AI elicited an OT secretion, resulting in an immediate increase of uterine contractions that lasted up to $30 \mathrm{~min}$ after insemination [48].

The literature investigating the dynamic transport of spermatozoa into the female genital tract clearly shows that uterine contractions play an important role in this process $[8,18,28,32]$. However, it is also well established that strong peristalsis does not facilitate sperm transport, but often reduces fertility [22, 25]. Indeed, the uterus responds to mating by increasing its contractile rate, but only transiently, for less than $1 \mathrm{~min}$ in the ewe $[12,42]$ and macaque $[14,44]$, or for no longer than $2 \mathrm{~min}$ in the rabbit [11] and woman [10]. Therefore, it is tempting to speculate that a secretion of OT altering the contractile rate of the uterus for a long period is detrimental to fertility in a number of species, including the ewe. For example, it has recently been shown that the administration of OT at the time of AI does not improve pregnancy rates, and tends to reduce fertility [36, 40, 45]. Furthermore, there is evidence that in an attempt to enhance sperm transport, such an OT treatment in the ewe considerably diminishes the number of spermatozoa recovered in the fallopian tubes after insemination [27]. On the contrary, since a reflex release of OT does not occur at mating in the ewe [12, 26], as in the cow [42], it is assumed that OT does not play a significant role in sperm transport in these species. These observations account for interspecies differences, since an OT release in response to mating has been demonstrated in sows [5], and results from a higher stimulation of the genital tract when intra-uterine deposition of semen occurs. Thus, in contrast with ewes, a physiological role for OT in sperm transport may be suggested in sows, because OT administration at the time of AI improved fertility in this species [33].

In conclusion, the present study indicates that a reflex release of OT can be elicited during routine procedures for cervical AI in the ewe. This secretion occurs in response to vaginal stimulation with the speculum, when it is difficult to observe the cervical entrance before introducing the AI catheter. Further studies are needed to determine whether this release of OT is responsible in part for the low rates of fertility attained in this species when a cervical procedure is employed for insemination.

\section{ACKNOWLEDGMENTS}

The authors would like to thank Thierry Fassier for performing artificial insemination, and gratefully acknowledge the help given by Michel Julien and the INRA shepherds (Brouessy, France) with sample processing and animal handling, Kais Al-Gubory and Christian Poirier for assistance during surgery.

\section{REFERENCES}

[1] Akaishi T., Robbins A., Sakuma Y., Sato Y., Neural inputs from the uterus to the paraventricular magnocellular neurons in the rat, Neurosci. Lett. 84 (1988) 57-62.

[2] Ayad V.J., Wathes D.C., Characterization of endometrial and myometrial oxytocin receptors in the non-pregnant ewe, J. Endocrinol. 123 (1989) 11-18

[3] Bontekoe E.H.M., Blacquiere J.F., Naaktgeboren C., Dieleman S.J., Willems P.P.M., Influence of environmental disturbances on uterine motility during pregnancy and parturition in rabbit and sheep, Behav. Processes 2 (1977) 41-73.

[4] Chemineau P., Cognié Y., Guérin Y., Orgeur P., Vallet J.C., Training manual on artificial insemination in sheep and goats, Food and Agriculture Organization of the United Nations (FAO), animal production and health paper 83 , Rome, 1991.

[5] Claus R., Schams D., Influence of mating and intra-uterine oestradiol infusion on peripheral oxytocin concentrations in the sow, J. Endocrinol. 126 (1990) 361-365.

[6] Conte-Devolx B., Oliver C., Giraud P., Castanas E., Boudouresque F., Gillioz P. Millet Y., Adrenocorticotropin, $\beta$-endorphin and corticosterone secretion in the Brattleboro rat, Endocrinology 110 (1982) 2097-2100.

[7] Dantzer R., Mormède P., Stress in farm animals: a need for reevaluation, J. Anim. Sci. 57 (1983) 6-18. 
[8] Drobnis E.Z., Overstreet J.W., Natural history of mammalian spermatozoa in the female reproductive tract, Oxf. Rev. Reprod. Biol. 14 (1992) $1-46$.

[9] Ferguson J.K.W., A study of the motility of the intact uterus at term, Surg. Gynecol. Obstet. 73 (1941) 359-366.

[10] Fox C.A., Wolff H.S., Baker J.A., Measurement of intra-vaginal and intra-uterine pressures during human coitus by radiotelemtry, J. Reprod. Fertil. 22 (1970) 243-251.

[11] Fuchs A.R., Uterine activity during and after mating in the rabbit, Fertil. Steril. 23 (1972) 915-923.

[12] Garcia-Villar R., Schams D., Alvinerie M., Laurentie M.P., Toutain P.L., Activity of the genital tract and plasma levels of oxytocin and cortisol at the time of mating in the ewe, J. Endocrinol. 105 (1985) 323-329.

[13] Gilbert C.L., Cripps P.J., Wathes D.C., Effect of oxytocin on the pattern of electromyographic activity in the oviduct and uterus of the ewe around oestrus, Reprod. Fertil. Dev. 4 (1992) 193-203.

[14] Goldfoot D.A., Westerborg-Van Loon H., Groeneveld W., Slob A.K., Behavioral and physiological evidence of sexual climax in the female stump-tailed macaques (Macaca arctoides), Science 208 (1980) 1477-1479.

[15] Gorewit R.C., Wachs E.A., Sagi R., Merrill W.G., Current concept on the role of oxytocin in milk ejection, J. Dairy Sci. 66 (1983) 2236-2250.

[16] Halbert G.W., Dobson H., Walton J.S., Buckrell B.C., The structure of the cervical canal of the ewe, Theriogenology 33 (1990) 977-979.

[17] Hancock J.L., McGovern P.T., The transport of sheep and goat spermatozoa in the ewe, J. Reprod. Fertil. 15 (1968) 283-287.

[18] Harper M.J.K., Gamete and zygote transport, in: Knobil E., Neill J.D. (Eds.), The Physiology of Reproduction, Raven Press, New York, 1994 pp. 123-187.

[19] Homeida A.M., Cooke R.G., Biological halflife of oxytocin in the goat, Res. Vet. Sci. 37 (1984) 364-365.

[20] Kendrick K., Keverne E.B., Hinton M.R.. Goode J.A., Cerebral spinal fluid and plasma concentrations of oxytocin and vasopressin during parturition and vaginocervical stimulation in the sheep, Brain Res. Bull. 26 (1991) 803-807.

[21] Krehbiel D., Poindron P., Levy F., Prud'homme M.J., Peridural anesthesia disturbs maternal behavior in primiparous and multiparous parturient ewes, Physiol. Behav. 40 (1987) 463-472.

[22] Kunz G., Beil D., Deininger H., Wildt L., Leyendecker G., The dynamics of rapid sperm transport through the female genital tract: evidence from vaginal sonography of uterine peristalsis and hyterosalpingoscintigraphy, Human Reprod. 11 (1996) 627-632.

[23] Lehrer A.R., Fischler H., Schindler H., Brown M., Telemetry of uterine motility in the cycling ewe, J. Anim. Sci. 38 (1974) 89-94.

[24] Lehrer A.R., Schindler H., Brown M., Fischler H., The effect of mating, artificial insemination, and fright on uterine motility of the oestrous ewe, Anim. Reprod. Sci. 1 (1979) 297-304.

[25] Leyendecker G., Kunz G., Wildt L., Beil D. Deininger H., Uterine hyperperistalsis and dysperistalsis as dysfunctions of the mechanism of rapid sperm transport in patients with endometriosis and infertility, Human Reprod. 11 (1996) 1542-1551.

[26] Lightfoot R.J., The contractile activity of the genital tract of the ewe in response to oxytocin and mating, J. Reprod. Fertil. 21 (1970) 376

[27] Lightfoot R.J., Restall B.J.G., Effects of site of insemination, sperm motility and genital tract contractions on transport of spermatozoa in the ewe, J. Reprod. Fertil. 26 (1971) 1-13.

[28] Lyons E.A., Taylor P.J., Zheng X.H., Ballard G., Levi C.S., Kredentser J.V., Characterization of subendometrial myometrial contractions throughout the menstrual cycle in normal fertile women, Fertil. Steril. 55 (1991) 771-775.

[29] Madill S., Troedsson M.H.T., Alexander S.L., Shand N., Santschi E.M., Irvine C.H.G., Simultaneous recording of pituitary oxytocin secretion and myometrial activity in estrous mares exposed to various breeding stimuli. Proc. 7 th Int. Symp. Equine Reprod. 1998, pp. 93-94.

[30] Marnet P.G., Volland H., Pradelles P., Grassi J., Beaufils M., Subpicogram determination of oxytocin by an enzyme immunoassay using acetylcholine esterase as label, J. Immunoassay 15 (1994) 35-53.

[31] Mattner P.E., Spermatozoa in the genital tract of the ewe. II. Distribution after coitus, Aust. J. Biol. Sci. 16 (1963) 688-694.

[32] Overstreet J.W., Cooper G.W., Sperm transport in the reproductive tract of the female rabbit. I. The rapid phase of transport, Biol. Reprod. 19 (1978) 101-114.

[33] Pena F.J., Dominguez J.C., Carbajo M., Anel L., Alegre B., Treatment of swine summer infertility syndrome by means of oxytocin under field conditions, Theriogenology 49 (1998) 829-836.

[34] Prud'homme M.J., Rousseau J.P., Study of uterine motor responses to vaginal and uterine stimulations in the ewe in oestrus, Reprod. Nutr. Dev. 22 (1982) 597-610.

[35] Richard P., Moos F., Freund-Mercier M.J., Bursting activity in oxytocin cells, in: Leng G (Ed.), Pulsatility in neuroendocrine systems, CRC Press, Boca Raton, 1988, pp. 75-99. 
[36] Rigby S., Hill J., Miller C., Thompson J., Varner D., Blanchard T, Administration of oxytocin immediately after insemination does not improve pregnancy rates in mares bred by fertile or subfertile stallions, Theriogenology 51 (1999) 1143-1150.

[37] Roberts J.S., Progesterone-inhibition of oxytocin release during vaginal distension: evidence for a central site of action, Endocrinology 89 (1971) 1137-1141.

[38] Roberts J.S., Share L., Oxytocin in plasma of pregnant, lactating and cycling ewes during vaginal stimulation, Endocrinology 83 (1968) 272-276.

[39] Sahmay S., Atasu T., Karacan I., The effect of intrauterine insemination on uterine activity, Int. J. Fertil. 35 (1990) 310-314.

[40] Sayre B.L., Lewis G.S., Fertility and ovum fertilization rate after laparoscopic or transcervical intrauterine artificial insemination of oxytocin-treated ewes, Theriogenology 48 (1997) 267-275

[41] Schams D., Schmidt-Polex B., Kruse V., Oxytocin determination by radioimmunoassay in cattle I. Method and preliminary physiological data, Acta Endocrinol. 92 (1979) 258-270

[42] Schams D., Baumann G., Leidl W., Oxytocin determination by radioimmunoassay in cattle. II. Effect of mating and stimulation of the genital tract in bulls, cows and heifers, Acta Endocrinol. 99 (1982) 218-223.

[43] Scheldrick E.L., Flint A.P., Circulating concentrations of oxytocin during the estrous cycle and early pregnancy in sheep, Prostaglandins 22 (1981) 631-636.

[44] Slob A.K., Groeneveld W.H., Van der Werff Ten Bosch J.J., Physiological changes during copulation in male and female stumptail macaques (Macaca arctoides), Physiol. Behav. 38 (1986) 891-895.

[45] Stellflug J.N., Wulster-Radcliffe M.C., Hensley E.L., Cowardin E.A., Seals R.C., Lewis G.S., Oxytocin-induced cervical dilation and cervical manipulation in sheep: effects of laparoscopic artificial insemination, J. Anim. Sci. 79 (2001) 568-573.

[46] Thibault C., Witenberger-Torrès S., Oxytocin and sperm transport in the ewe, Int. J. Fertil. 12 (1967) 412-415.

[47] Toutain P.L., Marnet P.G., Laurentie M.P. Garcia-Villar R., Ruckebusch Y., Direction of uterine contractions during estrus in ewes: a reevaluation, Am. J. Physiol. 249 (1985) R410-R416.

[48] Troedsson M.H.T., Liu I.K.M., Crabo B.G., Sperm transport and survival in the mare, Theriogenology 49 (1998) 905-915.

[49] Van der Weyden G.C., Myometrial activity in the non pregnant Texel ewe, Ph.D. thesis, Rijksuniversiteit Utrecht, The Netherlands, 1983.

[50] Webb R., Mitchell M.D., Falconer J., Robinson J.S., Temporal relationships between peripheral plasma concentrations of oxytocin, progesterone and 13, 14-dihydro-15-keto-prostaglandin F2 alpha during the oestrous cycle and early pregnancy in the ewe, Prostaglandins 22 (1981) 443-453. 